\title{
Association of FGFR2 and PI3KCA genetic variants with the risk of breast cancer in a Chinese population
}

This article was published in the following Dove Press journal: Cancer Management and Research

\author{
Yang Wang ${ }^{1,2}$ \\ Haiyu Zhang ${ }^{3}$ \\ Mingzhen Lin $^{2}$ \\ Yongsheng Wang ${ }^{4,5}$
}

'Shandong Cancer Hospital Affiliated to Shandong University, Jinan, Shandong, China; ${ }^{2}$ Department of Galactophore Surgery, Weifang People's Hospital, Weifang, Shandong, China; ${ }^{3}$ Department of Antenatal Diagnosis, Weifang People's Hospital, Weifang, Shandong, China; ${ }^{4}$ Breast Cancer Center, Shandong Cancer Hospital Affiliated to Shandong University, Jinan, Shandong, China; ${ }^{5}$ Shandong Academy of Medical Sciences, Jinan, Shandong, China
Correspondence: Yongsheng Wang Breast Cancer Center, Shandong Cancer Hospital Affiliated to Shandong University, 440 Jiyan Road, Jinan,

Shandong 2501 I7, China

Tel +8653187984777

Email yshengsd@163.com
Purpose: Genome-wide association studies have found plenty of single nucleotide polymorphisms (SNPs) which are associated with breast cancer risk. SNPs in FGFR2 are mostly identified. However, the association between PI3KCA SNP and breast cancer risk remains largely unknown. The aim of this study was to investigate the significance of FGFR2 and PI3KCA genetic variants in breast cancer and their association with prognosis.

Methods: We performed genotyping of 328 breast cancer patients and 389 healthy controls. Then, we evaluated the associations of FGFR2 rs1219648 and PI3KCA rs6443624 with the susceptibility and clinicopathological features of breast cancer. Kaplan-Meier curve with log-rank test was performed to determine the prognostic values of FGFR2 rs1219648 and PI3KCA rs6443624.

Results: The results indicated that genotype frequencies of rs1219648 and rs6443624 were significantly different between breast cancer patients and healthy controls. Furthermore, PI3KCA rs6443624 A carriers and FGFR2 rs1219648 G carriers more frequently had advanced stages and shorter survival times.

Conclusion: The SNPs of FGFR2 rs1219648 and PI3KCA rs6443624 may contribute to the identification of breast cancer patients at risk of more aggressive disease and may be potential prognostic factors in breast cancer in a Chinese population.

Keywords: rs1219648, rs6443624, breast cancer, prognosis

\section{Introduction}

Breast cancer (BC) is the most common malignancy and the first leading cause of cancer-related death among women worldwide. ${ }^{1}$ In China, over 272,400 new cases were diagnosed and there were 70,700 deaths in 2015, and the incidence has increased annually. ${ }^{2}$ Many BC risk factors have been identified, such as serum hormone levels, dietary and family history. ${ }^{3-5}$ It was reported that genes (BRCA1/2, ATM et al) inherited from family significantly increased susceptibility to $\mathrm{BC}$, and make up a large proportion of BC cases. ${ }^{6}$

Among different risk factors, RAS/MAPK and PI3K/AKT pathways through FGFs are widely recognized to be involved in the initiation and progression of $\mathrm{BC}$. ${ }^{7}$ FGFR2 is widely overexpressed in BC cell lines and tumor samples. ${ }^{8}$ Genome-wide association studies (GWAS) have suggested that a variety of FGFR2 single nucleotide polymorphisms (SNPs) were associated with BC risk. ${ }^{9,10}$ For instance, Liang et al performed genotyping and found that FGFR2 rs2981582, rs1219648, and rs2420946 were significantly associated with increased BC risk. ${ }^{11}$ Indeed, a variety of FGFR2 SNPs were found recently and were associated with elevated BC risk. However, considering the 
complex mechanisms of cancer development, we may need to combine several genes together to identify the cancer risk.

PI3KCA has been widely linked to cancer development. ${ }^{12,13}$ PI3KCA was reported to be frequently highly mutated in many types of cancers, such as esophageal cancer, colorectal cancer, and BC. ${ }^{14,15}$ Recently, PI3KCA genomic variants were identified as being associated with increased cancer risk. ${ }^{16}$ Park et $\mathrm{al}^{17}$ reported that PI3KCA rs2699905 and rs7640662 were significantly associated with melanoma patients' survival. Wang et $\mathrm{al}^{18}$ reported that PIK3CA rs2699887 showed notable associations with survival of endometrial cancer patients. However, the association between PI3KCA rs6443624 and $\mathrm{BC}$ risk and patient survival remains elusive.

In the current study, we focused on the combination of two reported cancer-related SNPs, FGFR2 rs1219648 and PI3KCA rs6443624. We investigated the correlations between these genes and $\mathrm{BC}$ risk and patient survival among female patients in China.

\section{Materials and methods Study population}

The study was approved by the Shandong Cancer Hospital Affiliated to Shandong University and written informed consent was obtained from all participants. A total of $328 \mathrm{BC}$ patients (aged 28-80 years, mean age 56 years) were analyzed retrospectively for the study from June 2010 to April 2011. The histology and TNM stages were classified according to the 7 th edition of the American Joint Committee on Cancer staging. Detailed clinicopathological features are presented in Table 1. The follow-up of each BC patient was performed at 3-month intervals in the first year and thereafter at 6-month intervals. The latest follow-up data in the study were obtained in December 2016. Additionally, 389 age-matched, healthy women were recruited as controls for the present study.

\section{Extraction of genomic DNA and genotyping}

An amount of $3 \mathrm{~mL}$ peripheral blood was obtained from patients and healthy controls for DNA extraction. The blood samples were treated with EDTA-K2 and stored at $-80^{\circ}$ until analysis. Genomic DNA were extracted with DNA Extraction Kits (Tiangen, Beijing, China) according to the instructions of the manufacturer.

Genotyping of rs1219648 and rs6443624 was carried out using pre-designed TaqMan SNP Genotyping assays (C_2917314_20, and C_2917314_20) as described previously. ${ }^{19}$ In brief, $10 \mu \mathrm{L}$ reaction solution containing $5 \mathrm{ng}$ genomic DNA and TaqMan Master Mix was performed Geno-
Table I Clinicopathologic parameters of breast cancer patients

\begin{tabular}{ll}
\hline Parameters & Case number \\
\hline Overall & 328 \\
Age (years) & \\
$\leq 50$ & 88 \\
$>50$ & 240 \\
Tumor size (cm) & \\
$\leq 2$ & 72 \\
$>2$ & 256 \\
Stage & \\
I+II & 234 \\
III & 94 \\
Grade & \\
I+II & 138 \\
III & 190 \\
Lymph node invasion & \\
No & 157 \\
Yes & 171 \\
ER status & \\
Negative & 146 \\
Positive & 182 \\
PR status & \\
Negative & 139 \\
Positive & 189 \\
HER2 status & \\
Negative & 242 \\
Positive & 86 \\
\hline
\end{tabular}

typing assay. PCR was performed with an ABI7500 (Thermo Fisher Scientific, Waltham, MA, USA). As quality control, approximately $10 \%$ of the samples were randomly used to repeat the reaction, and the results were $100 \%$ concordant.

\section{Statistical analysis}

The Hardy-Weinberg equilibrium was assessed in controls using asymptotic $\chi^{2}$ test. Fisher's exact test was performed to test the association between FGFR2 and PI3KCA genotypes in cases and controls. The strength of associations in FGFR2 and PI3KCA genotypes in BC risk was measured by binary logistic regression analysis and ORs and 95\% CIs. The overall survival was depicted by Kaplan-Meier method followed by the log-rank test. Multivariate Cox regression analyses were performed to assess the clinicopathological features in evaluating BC prognosis. All statistical analyses were performed with SPSS 21.0. A $p$-value less than 0.05 was considered statistically significant.

\section{Results}

\section{The association between FGFR2 rs I 219648 and PI3KCA rs6443624 and BC risk}

We performed the TaqMan allelic discrimination assay (details in Supplementary materials) and firstly, we found no 
deviations from Hardy-Weinberg equilibrium in both controls and cases; data shown in Table 2 ( $p>0.05)$.

Then, the allele and genotype distribution of FGFR2 rs 1219648 and PI3KCA rs6443624 in controls and BC cases revealed that the FGFR2 rs1219648 GG allele was significantly associated with $\mathrm{BC}$ risk by logistic regression analysis compared to AA genotype (OR: 2.40, 95\% CI: 1.32-4.36, $p=0.004$ ). Meanwhile, compared to patients carrying the CC allele for PI3KCA rs6443624, those with AC and AA had an OR of 1.33 (95\% CI: $0.90-1.96, p=0.154)$ and 1.95 (95\% CI: 1.28-2.96, $p=0.002$ ), respectively, suggesting that PI3KCA rs6443624 AA allele was significantly associated with the risk of BC. Moreover, we determined the dominant models of FGFR2 rs1219648 and PI3KCA rs6443624 and found that PI3KCA rs6443624 AA/AC genotype was significantly correlated with $\mathrm{BC}$ risk (Table 2).

\section{Association between FGFR2 rs 1219648 or PI3KCA rs6443624 and BC clinicopathological features}

To further evaluate the significance of FGFR2 rs1219648 or PI3KCA rs6443624 in BC, we assessed the association between these two SNPs and clinicopathological features, including age, tumor size, clinical stage, grade, lymph node invasion status, ER, PR, and HER2 status. The results indicated that PI3KCA rs6443624 AC allele was significantly correlated with advanced stage while AA allele was correlated with high grade. Also, the PI3KCA rs6443624 dominant model was notably correlated with advanced stage (Table 3).

For FGFR2 rs1219648, the AG allele had a significantly higher distribution in $\mathrm{BC}$ patients with advanced stage. Moreover, the FGFR2 rs1219648 dominant model also showed significantly higher risk of advanced stage (Table 4).

\section{FGFR2 rs I 219648 predicts poor prognosis of $B C$ patients}

To evaluate the prognostic significance of FGFR2 rs 1219648 or PI3KCA rs6443624 in BC patients, we performed KaplanMeier analysis with log-rank test to measure the patients' survival with different alleles. Intriguingly, we noticed that relative to patients with FGFR2 rs1219648 AA allele, those with AG and GG had shorter survival times ( $p=0.006$, Figure 1). However, patients with PI3KCA rs6443624 showed no difference between each allele ( $p=0.275$, Figure 2 ). Moreover, we performed multivariate analysis with stepwise Cox regression model and found that clinical stage, ER and PR status could be significant prognosticators (Table 5).

\section{Discussion}

In the present study, we evaluated the impact of FGFR2 and PI3KCA polymorphisms on BC patients. Recently, GWAS have identified a variety of genetic variants which were associated with BC risk. ${ }^{20,21}$ FGFR2 belongs to the FGF receptor family. The ligands, FGFs, could initiate the downstream signals and then modulate cell migration, angiogenesis, and growth. ${ }^{22}$ Among these, FGFR2 rs1219648 was reported to be related with BC development. ${ }^{23}$ Mechanically, it was demonstrated that rs 1219648 altered the transcription activity of FGFR2. Since this SNP was presented in the promoter region of FGFR2 gene, we thought it might up-regulate the expression of FGFR2, and high expression of FGFR2 promoted BC progression. ${ }^{24,25}$ Previous studies have revealed that FGFR2 rs1219648 was highly associated with BC lymph node metastasis, but showed no significant difference between healthy individuals and BC patients. ${ }^{26}$ However, our data suggested that FGFR2 rs1219648 was notably related to high risk of BC. Moreover, the AG/GG alleles were significantly associated

Table 2 Genotype frequencies of FGFR2 rs 1219648 and PI3KCA rs6443624 single nucleotide polymorphisms in patients and healthy controls

\begin{tabular}{lllll}
\hline Genotype & $\begin{array}{l}\text { Controls (\%) } \\
\mathbf{n = 3 8 9}\end{array}$ & $\begin{array}{l}\text { Cases (\%) } \\
\mathbf{n = 3 2 8}\end{array}$ & OR (95\% Cl) & p-value \\
\hline FGFR2 rs I219648 & $224(57.6)$ & $167(50.9)$ & 1.00 \\
AA & $146(37.5)$ & $127(38.7)$ & $1.17(0.86-1.59)$ & 0.331 \\
AG & $19(4.9)$ & $34(10.4)$ & $2.40(1.32-4.36)$ & 0.004 \\
GG & $165(42.4)$ & $161(49.1)$ & $1.31(0.98-1.76)$ & 0.074 \\
AG+GG & & & & \\
PI3KCA rs6443624 & $97(24.9)$ & $58(17.7)$ & 1.00 & \\
CC & $189(48.6)$ & $150(45.7)$ & $1.33(0.90-1.96)$ & 0.154 \\
AC & $103(26.5)$ & $120(36.6)$ & $1.95(1.28-2.96)$ & 0.002 \\
AA & $292(75.1)$ & $270(82.3)$ & $1.55(1.07-2.23)$ & 0.019 \\
AA+AC & & & & \\
\hline
\end{tabular}


Table 3 Association between PI3KCA rs6443624 and clinicopathological features of 328 breast cancer patients

\begin{tabular}{|c|c|c|c|c|}
\hline \multirow[t]{2}{*}{ Parameters } & \multicolumn{4}{|c|}{ PI3KCA rs6443624 } \\
\hline & CC & $A C$ & AA & $\mathbf{A C}+\mathbf{A A}$ \\
\hline \multicolumn{5}{|l|}{ Age (years) } \\
\hline$\leq 50 />50$ & $14 / 44$ & $42 / 108$ & $32 / 88$ & $74 / 196$ \\
\hline OR $(95 \% \mathrm{Cl})$ & 1.00 & $0.82(0.4|-| .65)$ & $0.88(0.42-1.8 I)$ & $0.84(0.44-1.63)$ \\
\hline $\mathrm{R}^{2}$ value & & $1.52 \mathrm{E}-3$ & $7.29 \mathrm{E}-4$ & $7.84 \mathrm{E}-4$ \\
\hline$p$-value & & 0.573 & 0.718 & 0.610 \\
\hline \multicolumn{5}{|l|}{ Tumor size $(\mathrm{cm})$} \\
\hline$\leq 2 />2$ & $10 / 48$ & $40 / 110$ & $22 / 98$ & $62 / 208$ \\
\hline OR $(95 \% \mathrm{Cl})$ & 1.00 & $0.57(0.27-1.24)$ & $0.93(0.4 \mathrm{I}-2.1 \mathrm{I})$ & $0.79(0.33-1.46)$ \\
\hline $\mathrm{R}^{2}$ value & & $9.80 \mathrm{E}-3$ & I.69E-4 & $2.8 \mathrm{IE}-3$ \\
\hline$p$-value & & 0.154 & 0.859 & 0.340 \\
\hline \multicolumn{5}{|l|}{ Stage } \\
\hline$|+| I / I I+\mid I V$ & $49 / 9$ & $106 / 44$ & $87 / 33$ & $193 / 77$ \\
\hline OR $(95 \% \mathrm{Cl})$ & 1.00 & $2.26(1.02-4.99)$ & $2.07(0.91-4.67)$ & $2.17(1.05-4.49)$ \\
\hline $\mathrm{R}^{2}$ value & & $2.02 \mathrm{E}-2$ & $1.74 \mathrm{E}-2$ & $1.37 \mathrm{E}-2$ \\
\hline$p$-value & & 0.040 & 0.078 & $0.034 *$ \\
\hline \multicolumn{5}{|l|}{ Grade } \\
\hline $\mathrm{I}+\mathrm{II} / \mathrm{III}$ & $31 / 27$ & $63 / 87$ & $44 / 76$ & $107 / 163$ \\
\hline OR $(95 \% \mathrm{Cl})$ & 1.00 & $1.59(0.86-2.92)$ & $1.98(1.05-3.75)$ & $1.75(0.99-3.10)$ \\
\hline$R^{2}$ value & & I.06E-2 & $2.53 \mathrm{E}-2$ & I.I4E-2 \\
\hline$p$-value & & 0.137 & 0.034 & 0.053 \\
\hline \multicolumn{5}{|l|}{ Lymph node invasion } \\
\hline No/yes & $32 / 26$ & $76 / 74$ & $51 / 69$ & $126 / 143$ \\
\hline OR $(95 \% \mathrm{Cl})$ & 1.00 & $1.20(0.65-2.20)$ & $1.67(0.89-3.13)$ & $1.55(0.88-2.75)$ \\
\hline$R^{2}$ value & & I.60E-3 & I.42E-2 & $7.06 \mathrm{E}-3$ \\
\hline$p$-value & & 0.560 & 0.112 & 0.129 \\
\hline \multicolumn{5}{|l|}{ ER status } \\
\hline Negative/positive & $24 / 34$ & $61 / 89$ & $61 / 59$ & $122 / 148$ \\
\hline OR $(95 \% \mathrm{Cl})$ & 1.00 & $1.03(0.56-1.91)$ & $0.68(0.36-1.29)$ & $0.86(0.48-1.52)$ \\
\hline$R^{2}$ value & & $4.90 \mathrm{E}-5$ & $7.92 \mathrm{E}-3$ & $8.4 I E-4$ \\
\hline$p$-value & & 0.925 & 0.237 & 0.597 \\
\hline \multicolumn{5}{|l|}{ PR status } \\
\hline Negative/positive & $22 / 36$ & $60 / 90$ & $57 / 63$ & $117 / 153$ \\
\hline OR $(95 \% \mathrm{Cl})$ & 1.00 & $0.92(0.49-\mid .7 I)$ & $0.68(0.36-1.28)$ & $0.80(0.45-1.43)$ \\
\hline $\mathrm{R}^{2}$ value & & $3.61 \mathrm{E}-4$ & $8.10 \mathrm{E}-3$ & $1.76 \mathrm{E}-3$ \\
\hline$p$-value & & 0.784 & 0.228 & 0.450 \\
\hline \multicolumn{5}{|l|}{ HER2 status } \\
\hline Negative/positive & $42 / 16$ & $|19 / 3|$ & $81 / 39$ & $200 / 70$ \\
\hline OR $(95 \% \mathrm{Cl})$ & 1.00 & $0.68(0.34-1.38)$ & $1.26(0.63-2.52)$ & $0.92(0.49-1.74)$ \\
\hline $\mathrm{R}^{2}$ value & & $5.48 \mathrm{E}-3$ & $2.50 \mathrm{E}-3$ & I.96E-4 \\
\hline$p$-value & & 0.285 & 0.506 & 0.794 \\
\hline
\end{tabular}

Note: $* p<0.05$, as compared to CC genotype.

with advanced stage and poor prognosis, which has not been reported previously. These results might be attributable to the different study population.

$\mathrm{PI} 3 \mathrm{KCA} / \mathrm{Akt}$ signaling is critical in many types of cancers, such as colorectal cancer, BC, and osteosarcoma. ${ }^{27,28}$ Also, somatic mutations in PI3KCA have been commonly identified in many types of cancers. ${ }^{29,30}$ A previous study reported that a majority of mutations happened in exon 20 , and some missense mutations and silent mutations were found in BC patients. ${ }^{31}$ PI3KCA rs17849079 was more frequently found in $\mathrm{BC}$ patients compared with disease-free controls. However, Stevens et $\mathrm{al}^{32}$ indicated that common variations in PI3KCA did not have a strong influence on $\mathrm{BC}$ as the patients were mostly Caucasian, and rs1607237 was associated with a decreased risk. The rs6443624 SNP located in the intron of PI3KCA, might affect the binding of transcription factors and alter the splicing patterns or transcription of the PIK3CA gene. ${ }^{18}$ In our study on a Chinese population, we suggested that PI3KCA rs6443624 was significantly associated with the risk of $\mathrm{BC}$, and $\mathrm{AC} /$ 
Table 4 Association between FGFR2 rs I 19648 and clinicopathological features of 328 breast cancer patients

\begin{tabular}{|c|c|c|c|c|}
\hline \multirow[t]{2}{*}{ Parameters } & \multicolumn{4}{|c|}{ FGFR2 rs I 2 I 9648} \\
\hline & AA & AG & GG & $\mathbf{A G}+\mathbf{G G}$ \\
\hline \multicolumn{5}{|l|}{ Age (years) } \\
\hline$\leq 50 />50$ & $39 / 128$ & $35 / 92$ & $14 / 20$ & $49 / 112$ \\
\hline OR $(95 \% \mathrm{Cl})$ & 1.00 & $0.80(0.47-1.36)$ & $0.44(0.20-0.94)$ & $0.70(0.43-1.12)$ \\
\hline $\mathrm{R}^{2}$ value & & $2.30 \mathrm{E}-3$ & $2.3 \mathrm{IE}-2$ & $6.40 \mathrm{E}-3$ \\
\hline$p$-value & & 0.410 & 0.032 & 0.148 \\
\hline \multicolumn{5}{|l|}{ Tumor size (cm) } \\
\hline$\leq 2 />2$ & $42 / 125$ & $20 / 107$ & $10 / 24$ & $30 / 131$ \\
\hline OR $(95 \% \mathrm{Cl})$ & 1.00 & $1.80(1.00-3.25)$ & $0.81(0.37-1.82)$ & $\mathrm{I} .47$ (0.87-2.49) \\
\hline$R^{2}$ value & & I.30E-2 & $1.29 \mathrm{E}-3$ & $6.24 \mathrm{E}-3$ \\
\hline$p$-value & & 0.05 & 0.61 & 0.154 \\
\hline \multicolumn{5}{|l|}{ Stage } \\
\hline $\mathrm{I}+\mathrm{II} / \mathrm{III+IV}$ & $129 / 38$ & $84 / 43$ & $21 / 13$ & $105 / 56$ \\
\hline OR $(95 \% \mathrm{Cl})$ & 1.00 & $1.74(1.04-2.91)$ & $2.10(0.96-4.59)$ & $1.82(1.11-2.94)$ \\
\hline$R^{2}$ value & & I.5IE-2 & I.77E-2 & I.77E-2 \\
\hline$p$ value & & $0.035^{*}$ & 0.059 & $0.016^{*}$ \\
\hline \multicolumn{5}{|l|}{ Grade } \\
\hline I+II/III & $62 / 105$ & $70 / 57$ & $6 / 28$ & $76 / 85$ \\
\hline OR $(95 \% \mathrm{Cl})$ & 1.00 & $0.48(0.30-0.77)$ & $2.76(1.08-7.03)$ & $0.66(0.43-1.03)$ \\
\hline $\mathrm{R}^{2}$ value & & $3.20 \mathrm{E}-2$ & $2.37 \mathrm{E}-2$ & I.04E-2 \\
\hline$p$-value & & $0.002^{*}$ & $0.029 *$ & 0.065 \\
\hline \multicolumn{5}{|l|}{ Lymph node invasion } \\
\hline No/Yes & $87 / 80$ & $58 / 69$ & $12 / 22$ & $70 / 91$ \\
\hline OR $(95 \% \mathrm{Cl})$ & 1.00 & $1.29(0.82-2.06)$ & $1.99(0.93-4.29)$ & $1.41(0.92-2.18)$ \\
\hline $\mathrm{R}^{2}$ value & & 4. $10 \mathrm{E}-3$ & I.59E-2 & $7.40 \mathrm{E}-3$ \\
\hline$p$-value & & 0.275 & 0.074 & 0.118 \\
\hline \multicolumn{5}{|l|}{ ER status } \\
\hline Negative/positive & $74 / 93$ & $55 / 72$ & $17 / 17$ & $72 / 89$ \\
\hline OR $(95 \% \mathrm{Cl})$ & 1.00 & $1.04(0.65-1.66)$ & $0.80(0.38-1.67)$ & $0.98(0.64-1.52)$ \\
\hline $\mathrm{R}^{2}$ value & & I.00E-4 & $1.85 \mathrm{E}-3$ & I.60E-5 \\
\hline$p$-value & & 0.864 & 0.544 & $0.94 I$ \\
\hline \multicolumn{5}{|l|}{ PR status } \\
\hline Negative/positive & $65 / 102$ & $58 / 69$ & $16 / 18$ & $74 / 87$ \\
\hline OR $(95 \% \mathrm{Cl})$ & 1.00 & $0.76(0.48-1.21)$ & $0.72(0.34-I .5 I)$ & $0.75(0.48-1.16)$ \\
\hline$R^{2}$ value & & $4.62 \mathrm{E}-3$ & $3.84 \mathrm{E}-3$ & $5.04 \mathrm{E}-3$ \\
\hline$p$-value & & 0.245 & 0.378 & 0.197 \\
\hline \multicolumn{5}{|l|}{ HER2 status } \\
\hline Negative/positive & $118 / 49$ & $94 / 33$ & $30 / 4$ & $124 / 37$ \\
\hline OR $(95 \% \mathrm{Cl})$ & 1.00 & $0.85(0.50-1.42)$ & $0.32(0.11-0.96)$ & $0.72(0.44-1.18)$ \\
\hline $\mathrm{R}^{2}$ value & & I.37E-3 & $2.25 \mathrm{E}-2$ & $5.18 \mathrm{E}-3$ \\
\hline$p$-value & & 0.525 & $0.034 *$ & 0.190 \\
\hline
\end{tabular}

Note: $* p<0.05$, as compared to AA genotype.

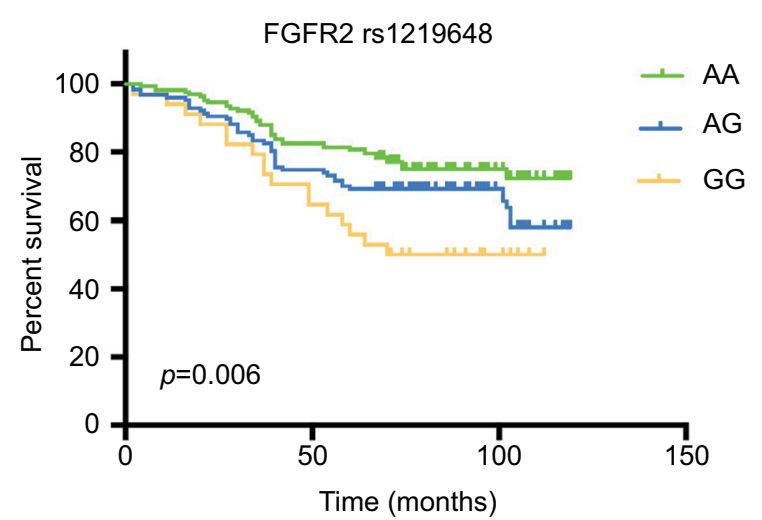

Figure I The Kaplan-Meier curve illustrates overall survival based on FGFR2 allele status.

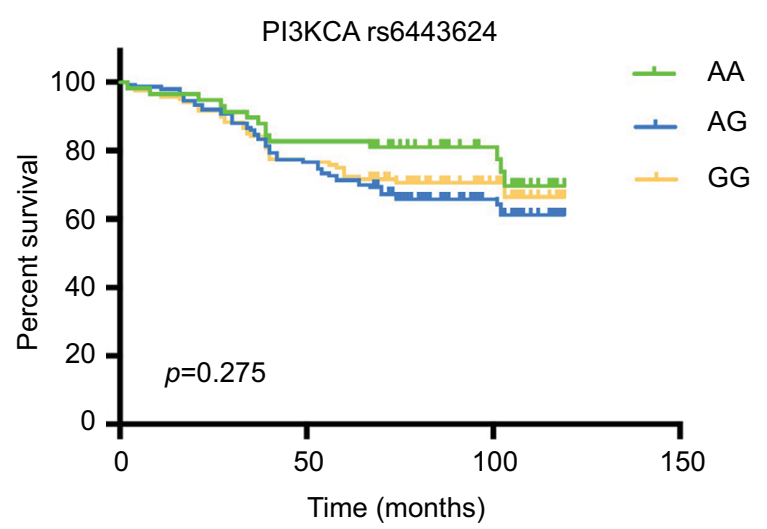

Figure 2 The Kaplan-Meier curve illustrates overall survival based on PI3KCA allele status. 
Table 5 Multivariate analysis for overall survival (stepwise Cox regression analysis)

\begin{tabular}{llll}
\hline Parameters & HR & $\mathbf{9 5 \% ~ C l ~}$ & $\mathbf{p}$ \\
\hline Age & 1.259 & $0.475-3.335$ & 0.643 \\
Tumor size & 0.856 & $0.549-1.337$ & 0.495 \\
Stage & 1.847 & $1.195-2.855$ & $0.006^{*}$ \\
Grade & 1.093 & $0.728-1.640$ & 0.670 \\
Lymph node invasion & 1.023 & $0.663-1.580$ & 0.917 \\
ER status & 0.638 & $0.421-0.968$ & $0.034^{*}$ \\
PR status & 0.317 & $0.121-0.833$ & $0.020^{*}$ \\
HER2 status & 1.083 & $0.573-2.068$ & $0.78 I$ \\
rsI219648 (AA vs. AG+GG) & 1.449 & $0.968-2.168$ & $0.07 I$ \\
rs6443624 (CC vs. AC+AA) & 1.273 & $0.720-2.250$ & 0.406 \\
\hline
\end{tabular}

Note: ${ }^{*}<0.05$.

AA alleles were associated with advanced stage, implying their biological functions, which need further investigation.

Moreover, we noticed that FGFR2 rs1219648 was significantly associated with poor BC prognosis, which has not been reported previously. However, no such association was found between PI3KCA rs6443624 and short survival time. A previous report showed that rs6443624 could be an independent predictor and prognostic factor in renal cell carcinoma patients. ${ }^{33}$ So, further study will be performed to confirm and validate this finding.

In conclusion, our results obtained from a cohort of Chinese BC patients, indicated that FGFR2 rs1219648 and PI3KCA rs6443624 were significantly associated with BC risk and FGFR2 rs1219648 AG/GG alleles were associated with shorter survival. Therefore, detection of the SNPs might help to identify patients and predict prognosis.

\section{Disclosure}

The authors report no conflicts of interest in this work.

\section{References}

1. Siegel RL, Miller KD, Jemal A. Cancer statistics, 2016. CA Cancer J Clin. 2016;66(1):7-30.

2. Chen W, Zheng R, Baade PD, et al. Cancer statistics in China, 2015. CA Cancer J Clin. 2016;66(2):115-132.

3. Endogenous Hormones and Breast Cancer Collaborative Group, Key TJ, Appleby PN, et al. Sex hormones and risk of breast cancer in premenopausal women: a collaborative reanalysis of individual participant data from seven prospective studies. Lancet Oncol. 2013;14(10):1009-1019.

4. Farvid MS, Cho E, Chen WY, Eliassen AH, Willett WC. Dietary protein sources in early adulthood and breast cancer incidence: prospective cohort study. BMJ. 2014;348:g3437.

5. Couch FJ, Hart SN, Sharma P, et al. Inherited mutations in 17 breast cancer susceptibility genes among a large triple-negative breast cancer cohort unselected for family history of breast cancer. J Clin Oncol. 2015;33(4):304-311.

6. Tung N, Battelli C, Allen B, et al. Frequency of mutations in individuals with breast cancer referred for BRCA1 and BRCA2 testing using next-generation sequencing with a 25 -gene panel. Cancer. 2015;121(1):25-33.
7. Saini KS, Loi S, de Azambuja E, et al. Targeting the PI3K/AKT/mTOR and Raf/MEK/ERK pathways in the treatment of breast cancer. Cancer Treat Rev. 2013;39(8):935-946.

8. Tannheimer SL, Rehemtulla A, Ethier SP. Characterization of fibroblast growth factor receptor 2 overexpression in the human breast cancer cell line SUM-52PE. Breast Cancer Res. 2000;2(4):311-320.

9. Hunter DJ, Kraft P, Jacobs KB, et al. A genome-wide association study identifies alleles in FGFR2 associated with risk of sporadic postmenopausal breast cancer. Nat Genet. 2007;39(7):870-874.

10. Barnholtz-Sloan JS, Shetty PB, Guan X, et al. FGFR2 and other loci identified in genome-wide association studies are associated with breast cancer in African-American and younger women. Carcinogenesis. 2010;31(8):1417-1423.

11. Liang J, Chen P, Hu Z, et al. Genetic variants in fibroblast growth factor receptor 2 (FGFR2) contribute to susceptibility of breast cancer in Chinese women. Carcinogenesis. 2008;29(12):2341-2346.

12. Ma YY, Wei SJ, Lin YC, et al. PIK3CA as an oncogene in cervical cancer. Oncogene. 2000;19(23):2739-2744.

13. Engelman JA, Chen L, Tan X, et al. Effective use of PI3K and MEK inhibitors to treat mutant Kras G12D and PIK3CA H1047R murine lung cancers. Nat Med. 2008;14(12):1351-1356.

14. De Roock W, De Vriendt V, Normanno N, Ciardiello F, Tejpar S. KRAS, BRAF, PIK3CA, and PTEN mutations: implications for targeted therapies in metastatic colorectal cancer. Lancet Oncol. 2011;12(6): 594-603.

15. Campbell IG, Russell SE, Choong DY, et al. Mutation of the PIK3CA gene in ovarian and breast cancer. Cancer Res. 2004;64(21):7678-7681.

16. Ogino S, Lochhead P, Giovannucci E, et al. Discovery of colorectal cancer PIK3CA mutation as potential predictive biomarker: power and promise of molecular pathological epidemiology. Oncogene. 2014;33(23):2949-2955.

17. Park JY, Amankwah EK, Anic GM, et al. Gene variants in angiogenesis and lymphangiogenesis and cutaneous melanoma progression. Cancer Epidemiology Biomarkers and Prevention. 2013;22(5):827-834.

18. Wang LE, Ma H, Hale KS, et al. Roles of genetic variants in the $\mathrm{PI} 3 \mathrm{~K}$ and RAS/RAF pathways in susceptibility to endometrial cancer and clinical outcomes. J Cancer Res Clin Oncol. 2012;138(3): 377-385.

19. Jara L, Gonzalez-Hormazabal P, Cerceno K, et al. Genetic variants in FGFR2 and MAP3K1 are associated with the risk of familial and earlyonset breast cancer in a South-American population. Breast Cancer Res Treat. 2013;137(2):559-569.

20. Turnbull C, Ahmed S, Morrison J, et al. Genome-wide association study identifies five new breast cancer susceptibility loci. Nat Genet. 2010;42(6):504-507.

21. Shan J, Mahfoudh W, Dsouza SP, et al. Genome-Wide Association Studies (GWAS) breast cancer susceptibility loci in Arabs: susceptibility and prognostic implications in Tunisians. Breast Cancer Res Treat. 2012;135(3):715-724.

22. Penault-Llorca F, Bertucci F, Adelaide J, et al. Expression of FGF and FGF receptor genes in human breast cancer. Int $J$ Cancer. 1995;61(2):170-176.

23. Zhang J, Qiu LX, Wang ZH, et al. Current evidence on the relationship between three polymorphisms in the FGFR2 gene and breast cancer risk: a meta-analysis. Breast Cancer Res Treat. 2010;124(2): 419-424.

24. Meyer KB, Maia AT, O'Reilly M, et al. Allele-specific up-regulation of FGFR2 increases susceptibility to breast cancer. PLoS Biol. 2008;6(5):e108.

25. Huijts PE, van Dongen M, de Goeij MC, et al. Allele-specific regulation of FGFR2 expression is cell type-dependent and may increase breast cancer risk through a paracrine stimulus involving FGF10. Breast Cancer Res. 2011;13(4):R72.

26. Chen XH, Li XQ, Chen Y, Feng YM. Risk of aggressive breast cancer in women of Han nationality carrying TGFB1 rs $1982073 \mathrm{C}$ allele and FGFR2 rs1219648 G allele in North China. Breast Cancer Res Treat. 2011;125(2):575-582. 
27. Porta C, Paglino C, Mosca A. Targeting PI3K/Akt/mTOR signaling in cancer. Front Oncol. 2014;4:64.

28. Ying J, Xu Q, Liu B, et al. The expression of the PI3K/AKT/mTOR pathway in gastric cancer and its role in gastric cancer prognosis. Onco Targets Ther. 2015;8:2427-2433.

29. Hao Y, Samuels Y, Li Q, et al. Oncogenic PIK3CA mutations reprogram glutamine metabolism in colorectal cancer. Nat Commun. 2016; 7:11971.

30. Samuels Y, Wang Z, Bardelli A, et al. High frequency of mutations of the PIK3CA gene in human cancers. Science. 2004;304(5670):554.
31. Karakas B, Colak D, Kaya N, et al. Prevalence of PIK3CA mutations and the SNP rs17849079 in Arab breast cancer patients. Cancer Biol Ther. 2013;14(10):888-896.

32. Stevens KN, Garcia-Closas M, Fredericksen Z, et al. Evaluation of variation in the phosphoinositide-3-kinase catalytic subunit alpha oncogene and breast cancer risk. Br J Cancer. 2011;105(12):1934-1939.

33. Bodnar L, Stec R, Cierniak S, et al. Clinical usefulness of PI3K/Akt/ mTOR genotyping in companion with other clinical variables in metastatic renal cell carcinoma patients treated with everolimus in the second and subsequent lines. Ann Oncol. 2015;26(7):1385-1389.
Cancer Management and Research

\section{Publish your work in this journal}

Cancer Management and Research is an international, peer-reviewed open access journal focusing on cancer research and the optimal use of preventative and integrated treatment interventions to achieve improved outcomes, enhanced survival and quality of life for the cancer patient The manuscript management system is completely online and includes

\section{Dovepress}

a very quick and fair peer-review system, which is all easy to use. Visit $\mathrm{http}: / /$ www.dovepress.com/testimonials.php to read real quotes from published authors. 